\title{
SONS E IDEAIS PELA DEMOCRATIZAÇÃO DO ENSINO DE MÚSICA: VILLA- LOBOS NO INSTITUTO DE EDUCAÇÃO DO RIO DE JANEIRO
}

\author{
Ednardo Monteiro Gonzaga do Monti \\ Professor do Programa de Pós-graduação em Educação - PPGEd e do curso de Licenciatura em \\ Música da Universidade Federal do Piauí - UFPI; Doutor em Educação pela Universidade do \\ Estado do Rio de Janeiro - Proped/UERJ \\ https://orcid.org/0000-0003-3513-3316
}

\section{RESUMO}

Este estudo tem como horizonte as articulações políticas e pedagógicas do maestro Heitor VillaLobos com três signatários do Manifesto da Educação Nova (1932), no âmbito do Instituto de Educação do Rio de Janeiro; a saber, os intelectuais: Anísio Teixeira, Afrânio Peixoto e Fernando de Azevedo. Mobilizadas pelo conceito de documento/monumento de Le Goff (2010), as diferentes fontes do trabalho abarcam partituras, correspondências, escritas autobiográficas, manuais didáticos, relatórios e periódicos, além de duas entrevistas com ex-alunas da instituição no período em questão. Os documentos foram selecionados principalmente no Centro de Memória da Educação Brasileira, sediado no Instituto Superior de Educação do Rio de Janeiro. Como resultado dos contrapontos entre as propostas de Villa-Lobos e dos signatários, entendem-se as proximidades dos ideais. Porém, ao se tratar do Instituto, percebe-se que a conjuntura da instituição difere das comunidades educativas das classes populares. Sobretudo na medida em que era um exemplo prático de observância do modelo ideal de escola.

Palavras-chave: Villa-Lobos; Manifesto da Educação Nova; Educação Musical; Canto Orfeônico.

\section{SOUNDS AND IDEALS FOR THE DEMOCRATICIZATION OF MUSIC EDUCATION: VILLA-LOBOS AT THE INSTITUTO DE EDUCAÇÃO DO RIO DE JANEIRO}

\begin{abstract}
This study has as a horizon the political and pedagogical articulations of conductor Heitor VillaLobos with three signatories of the Manifesto da Educação Nova (1932), within the scope of the of Instituto de Educação do Rio de Janeiro; namely the intellectuals: Anísio Teixeira, Afrânio Peixoto and Fernando de Azevedo. Mobilized by Le Goff's document / monument concept (2010), different sources of work include scores, correspondences, autobiographical writings, didactic manuals, reports and periodicals, as well as two interviews with former students of the institution in that period. The documents were selected mainly at the Centro de Memória da Educação Brasileira, headquartered at the Instituto Superior de Educação do Rio de Janeiro. As a result of the counterpoints between Villa-Lobos and the signatories proposals, they are close to ideals. However, when dealing with the Institute, it is perceived that the conjuncture of the institution differs from the educational communities of the popular classes. Especially since it was a practical example of observance of the ideal model of school.
\end{abstract}

Keywords: Villa-Lobos; Manifesto da Educação Nova; Musical Education; Orpheonic Singing.

\section{SONS Y IDEAIS POR LA DEMOCRATIZACIÓN DE LA ENSEÑANZA DE MÚSICA: VILLA-LOBOS EN EL INSTITUTO DE EDUCACIÓN DEL RÍO DE JANEIRO}

\section{RESUMEN}

Este estudo tem como horizonte as articulações políticas e pedagógicas do maestro Heitor VillaLobos com três signatários do Manifesto da Educação Nova (1932), no âmbito do Instituto de Educação do Rio de Janeiro; a saber, os intelectuais: Anísio Teixeira, Afrânio Peixoto e Fernando 
de Azevedo. Mobilizadas pelo conceito de documento/monumento de Le Goff (2010), as diferentes fontes do trabalho abarcam partituras, correspondências, escritas autobiográficas, manuais didáticos, relatórios e periódicos, além de duas entrevistas com ex-alunas da instituição no período em questão. Os documentos foram selecionados principalmente no Centro de Memória da Educação Brasileira, sediado no Instituto Superior de Educação do Rio de Janeiro. Como resultado dos contrapontos entre as propostas de Villa-Lobos e dos signatários, entendem-se as proximidades dos ideais. Porém, ao se tratar do Instituto, percebe-se que a conjuntura da instituição difere das comunidades educativas das classes populares. Sobretudo na medida em que era um exemplo prático de observância do modelo ideal de escola.

Palavras-chave: Villa-Lobos; Manifesto da Educação Nova; Educação Musical; Canto Orfeônico.

\section{INTRODUÇÃOO}

A memória tem sentido na medida em que permite pensar o presente; portanto vale resgatar a experiência [...] para pensar a educação brasileira hoje (CALAZANS apud FÁVERO, 2003, p.1272).

Conforme a epígrafe, neste trabalho a memória se articula com o contexto político contemporâneo, justificando-se a pertinência da investigação proposta pela relevância da democratização do ensino de música como componente curricular, tendo em vista a Lei 11.769/2008, que dispõe sobre a obrigatoriedade do ensino da música na educação básica. A referida norma jurídica altera a Lei no 9.394, de 20 de dezembro de 1996 - Lei de Diretrizes e Bases da Educação (LBD) -, cujo Artigo 26 passou a vigorar, desde agosto de 2008, acrescido do seguinte $\S 6^{\text {ㅇ: }}$ “A música deverá ser conteúdo obrigatório, mas não exclusivo, do componente curricular de que trata o $§ 2^{\circ}$ deste artigo" (BRASIL, 2008, p.1).

Porém, julgamos necessário esclarecer que o objetivo nesta pesquisa é analisar as questões pedagógicas, políticas e identitárias relacionadas às práticas orfeônicas do Instituto de Educação do Rio de Janeiro. Buscar-se-á compreendê-las por meio da História da Educação, como sugere António Nóvoa (2004). Em primeiro lugar para cultivar uma saudável consciência crítica que nos permita conjeturar novidades e manter o necessário distanciamento criterioso diante dos modismos pedagógicos que frequentemente nos assaltam e tentam nos dominar. Em segundo lugar, para fomentar a compreensão, a convivência entre as identidades múltiplas; aspectos que definem memórias, tradições, sentimentos de pertencimento e filiações; de comunidades reais e imaginárias, às quais, de distintas formas e no cumprimento de diferentes papeis, nós, sujeitos históricos, nos integramos. Em terceiro lugar, com a finalidade de pensar os indivíduos, em si, como protagonistas da história, permitindo-nos reavaliar nosso próprio lugar no curso dos acontecimentos. E, finalmente, para explicar que não há mudanças sem história. 
Nessa perspectiva, focalizam-se neste texto articulações políticas e pedagógicas do maestro Heitor Villa-Lobos (1887-1959) com três signatários do Manifesto da Educação Nova (1932) no âmbito do Instituto de Educação do Rio de Janeiro, a saber: os intelectuais Anísio Teixeira (1900-1971), Afrânio Peixoto (1876-1947) e Fernando de Azevedo (18941974). Vale destacar que, em 19 de março de 1932, pelo Decreto 3.810, a Escola Normal do Distrito Federal recebeu nova denominação: Instituto de Educação. Aproximadamente um ano antes, o então presidente da República, Getúlio Vargas (1882-1954), havia assinado o decreto 19.890, tornando obrigatório o Canto Orfeônico como disciplina em todas as escolas do Distrito Federal.

Essas aproximações não parecem ser apenas temporais, pois assim como o manifesto promovia uma defesa ousada da educação pública, laica e gratuita para todos, o projeto musical-pedagógico de Villa-Lobos também pretendia democratizar o acesso ao ensino da música, já que nesse período não havia aula dessa expressão artística em grande parte das escolas do Rio de Janeiro, capital da República.

As diferentes fontes do presente trabalho abarcam partituras, correspondências, autobiografias, manuais didáticos, relatórios, periódicos, bem como legislações e outros documentos oficiais selecionadas no Centro de Memória da Educação Brasileira - sediado no Instituto Superior de Educação do Rio de Janeiro -, no Museu Villa-Lobos, na Biblioteca do Conservatório Brasileiro de Música - Centro Universitário, no acervo histórico da Biblioteca Alberto Nepomuceno da Escola de Música da UFRJ, no Centro de Pesquisa e Documentação de História Contemporânea do Brasil da Fundação Getúlio Vargas - CPDOC/FGV e na Divisão de Música e Arquivo Sonoro da Biblioteca Nacional - DIMAS. Estes documentos são analisados com base no conceito de documento/monumento de Le Goff (2010), juntamente com o historiador francês entendese:

O documento é resultado de uma montagem, consciente ou inconsciente, da história, da época, da sociedade que o produziu e também das épocas sucessivas durante as quais continuou a existir. O documento é monumento, resulta do esforço das sociedades históricas para impor ao futuro determinada imagem de si próprias. O documento é produto da sociedade, que o fabricou segundo as relações de forças que nela detinham o poder. [...] Atualmente, a história transforma os documentos em monumentos e apresenta uma massa de elementos que é preciso isolar, reagrupar, tornar pertinentes, ser colocados em relação, constituídos em conjunto. O novo documento alargado, transformado 
deve ser tratado como um documento-monumento (LE GOFF, 2010, p. 538).

A associação da pesquisa documental com outras ferramentas de coleta de dados é muito apropriada no momento em que há objetivo de ratificação e validação de vestígios identificados por outras técnicas, porque "quando duas ou mais abordagens do mesmo problema produzem resultados similares, nossa confiança em que os resultados reflitam mais o fenômeno em que estamos interessados do que os métodos que usamos aumenta" (LUDKE E ANDRÉ, 1986, p. 39). Por esse motivo, numa segunda fase da investigação, visando fazer as entrevistas, procuramos no Estado do Rio de Janeiro alunos e professores de Música e Canto Orfeônico do Instituto de Educação, em uma seleção intencional, "isso significa que a amostra é selecionada levando-se em consideração as pessoas que podem efetivamente contribuir para o estudo" (LUDKE E ANDRÉ, 1986, p. 39).

Nesse sentido, por meio das entrevistas semiestruturada transcritas, as memórias de Josefina Figueiredo Antunes e Carolina Miguez Macedo - que emocionam, inspiraram e geram reflexões - são dialogadas com diferentes fontes documentais, mobilizadas para analisar as polifonias políticas, pedagógicas e identitárias das atividades musicais de Heitor Villa-Lobos no Instituto de Educação do Rio de Janeiro, na Era Vargas.

A harmonia do projeto orfeônico villalobiano com o documento de 1932, o Manifesto dos Pioneiros da Educação Nova, está relacionada com o apelo por uma profunda alteração, de dimensão nacional, no sistema educacional. Para os signatários, o padrão da educação vigente era elitista, concebido para as classes sociais mais favorecidas; portanto, o acesso à escola de qualidade era "um privilégio determinado pela condição econômica e social do indivíduo" (AZEVEDO, 1960, parágrafo 10). E, contrariando esse contexto de desigualdades, o Canto Orfeônico seria outra maneira de assegurar o ensino democrático, obrigatório e gratuito financiado pelo Estado. Uma prática musical coletiva no universo da "escola socializada". Segundo o Manifesto:

A educação nova, alargando a sua finalidade para além dos limites de classes, assume, com uma feição mais humana, a sua verdadeira função social, preparando-se para formar a 'hierarquia democrática' pela 'hierarquia das capacidades', recrutadas em todos os grupos sociais, a que se abrem as mesmas oportunidades de educação. Ela tem, por objeto, organizar e desenvolver os meios de ação durável com o fim de dirigir o desenvolvimento natural e integral do ser humano em cada uma das etapas de seu crescimento, de acordo com uma certa concepção de mundo. (AZEVEDO, 1960, parágrafo 10). 
Nessa perspectiva, a seguir buscamos interpretar algumas aproximações do projeto e da concepção musical-pedagógica villalobiana com as ideias de três professores, docentes do Instituto de Educação do Rio de Janeiro, intelectuais que assinaram o Manifesto dos Pioneiros: Anísio Teixeira, Afrânio Peixoto e Fernando de Azevedo.

\section{ANÍSIO TEIXEIRA: POR QUEM VEIO O CONVITE}

A opção, neste estudo, por Anísio Teixeira e Afrânio Peixoto, se dá pelo fato de esses educadores terem exercido cargos de gestão ligados ao Instituto no período da obrigatoriedade do Canto Orfeônico como uma disciplina e, também, no período de atuação do Maestro na instituição. Além disso, foram encontradas cartas trocadas entre Villa-Lobos, Afrânio Peixoto e Anísio Teixeira que podem ser entendidas como relatos que evidenciam redes de sociabilidade entre os signatários do Manifesto e Villa-Lobos, "mentor" da disciplina Música e Canto Orfeônico, regente do Orfeão Artístico do Instituto de Educação do Rio de Janeiro, e ainda gestor do projeto orfeônico em nível nacional.

Além das atividades do Instituto de Educação do Rio de Janeiro, Anísio Teixeira acompanhava de perto as concentrações orfeônicas; porque o signatário do Manifesto e Villa-Lobos tinham a educação nacionalista como algo em comum. No jornal O Globo, em 1933, aparece:

A grandiosidade de uma festa de educação cívica, de arte e fé. No campo
do Fluminense vibrou a alma nacional em expressões inéditas. Além da
regência, [...] as mãos dominadoras e os olhos hipnóticos de Villa-Lobos,
o grande educador brasileiro, não se podem deixar de ver realçados o
brilho e a galhardia com que se incorporaram a essa festa de ritmo as
bandas musicais do exército, polícia, bombeiros e batalhão naval.
Estiveram presentes o Sr. e Sra. Getúlio Vargas, cardeal D. Sebastião
Leme, professor Anísio Teixeira, Ministro da Marinha, secretários dos
ministérios. Dr. Amaral Peixoto, representando o interventor Pedro
Ernesto, e figuras de grande representação social. (FESTA, O Globo,
27/11/1933, p. 3).

A trajetória de Villa-Lobos como educador nas instituições públicas é bastante afeita às iniciativas de Anísio Teixeira, uma vez que o Maestro foi convidado oficialmente por ele, então diretor da Instrução Pública, para implantar e dirigir o Serviço de Educação Musical e Artística (SEMA). Instituído em 1932 e denominado, em 1936, como Superintendência de Educação Musical e Artística, com objetivo de ampliar e sistematizar o ensino da música. (CHERNAVSKY, 2003). A SEMA, sigla pela qual a superintendência ficou conhecida, era diretamente ligada e subordinada ao Departamento de Educação da Prefeitura do Distrito Federal, ou seja, ligada a Anísio Teixeira. Villa-Lobos foi o primeiro 
a ocupar a função de superintendente. A instituição ficou responsável pela supervisão, orientação e implantação do programa de ensino de música no Distrito Federal, envolvendo principalmente a formação de professores e o instituto. A aula magna foi ministrada em 10 de março de 1932. Villa-Lobos, ao narrar suas intenções como gestor da SEMA, menciona o signatário:

Em 1932, a convite do Diretor-Geral do Departamento de Educação Anísio Teixeira, fui investido nas funções de orientador de Música e Canto Orfeônico no Distrito Federal, e tive, como primeiros cuidados, a especialização e aperfeiçoamento do magistério, e a propaganda, junto ao público, da importância e utilidade do ensino de música. Reunindo os professores, compreendendo-lhes a sensibilidade $\mathrm{e}$ avaliando as possibilidades e recursos de cada um, ofereci-lhes cursos com acentuada finalidade pedagógica, dos quais, logo depois, surge o Orfeão dos Professores, onde, como nos cursos, ingressavam pessoas estranhas, atendendo à complexidade artística das organizações (VILLA-LOBOS, 1937, p. 6).

É importante destacar que o Orfeão de Professores do Distrito Federal aglutinava os membros do Orfeão Artístico do Instituto, portanto, muitas das vezes era na instituição que as peças e atividades orfeônicas soavam pela primeira vez (CONTIER, 1998). Nesse contexto, como o Instituto de Educação era uma casa aberta às novas práticas, inicialmente, alguns experimentos da SEMA ocorriam na instituição. Como explica Vidal (2001), as experiências pedagógicas inovadoras empreendidas nessa instituição aprofundavam e ampliavam um perfil de escola-laboratório na medida em que havia abertura de práticas de ensino inéditas ou em teste no Brasil.

Numa série publicada pelo Ministério da Educação, Presença de Villa-Lobos, Anísio Teixeira relata a importância do Maestro na educação. Para o então secretário da Instrução Pública da prefeitura do Distrito Federal, o músico conseguia “civilizar" por meio da arte. O signatário declarou a relevância do Maestro no projeto ao afirmar: "Nada me parecia mais importante do que essa integração da arte na educação popular, [porque] "Villa-Lobos fez-se educador de professores e crianças. Na realidade, um educador do povo pelo esforço maior da nossa integração em uma cultura própria e autóctone" (MINISTÉRIO DA EDUCAÇÃO, 1970, p.111).

O texto demonstra que Anísio Teixeira considerava o músico um "educador de professores", ou seja, alguém que era importante numa instituição de formação de professores, para educar os futuros docentes que multiplicariam a música como discurso cultural nacionalista integrador. Como relata Anísio: 
Para Villa-Lobos, o maior homem da História do Brasil foi José de Anchieta, considerado por ele como o verdadeiro precursor da educação musical. Ao que parece esta admiração se reflete no seu pensamento, como grande fonte propulsora da obra educacional de Villa-Lobos que o transformou de um grande homem dos palcos num gigante em luta pela educação social através da música (MINISTÉRIO DA EDUCAÇÃO, 1970, p.111).

Anísio Teixeira coloca o fazer pedagógico de Villa-Lobos no mesmo patamar do trabalho musical e evangelizador do Padre José de Anchieta. Em outras palavras, ancora o trabalho do músico republicano brasileiro num chamado vocacional que faz um homem, já "consagrado" nos nobres palcos do mundo, dedicar-se a uma "santa missão" musical, social, política e pedagógica. Anísio ainda destaca que os cidadãos que valorizam o Estado e que permanecem na luta pela educação popular no Brasil podem plenamente compreender o Maestro, "o vulto de sua obra, a importância de seus sacrifícios para assentar as bases de uma nação. Uma visão genial e moderna, aprendida de tão longe, é um privilégio nos processos de valorização da verdadeira cultura brasileira" (MINISTÉRIO DA EDUCAÇÃO, 1970, p.111).

Dessa forma, Anísio Teixeira parece afirmar que o ensino de Música, por meio de Heitor Villa-Lobos, estava em autêntica consonância com a educação buscada no período para formar cidadãos adaptados às modernidades do mundo e que era conveniente, nesse momento, a organização da formação de professores de Música e Canto Orfeônico. Isso, num período de mudanças, no qual a principal escola normal do Rio de Janeiro passou a ser chamada de Instituto de Educação, como um dos desdobramentos das metas de grandes reformas, fundamentadas no ideário republicano da educação para todos.

Nesse sentido, de escola para todos, Anísio afirmou que a "escola é a casa do povo, não em um sentido qualquer de simples retórica, mas no sentido realíssimo de reguladora social da ideia democrática” (TEIXEIRA, 1935, p. 180). Ou seja, uma ideia consonante com a proposta de Villa-Lobos, pois, uma vez implantado, o Canto Orfeônico e conjuntos, como os Orfeões Artísticos nas redes regulares de ensino, possibilitaria uma democratização da prática e do conhecimento musical, que passariam a ser disseminados nos diferentes segmentos da sociedade (VILLA-LOBOS, 1946). Entretanto, o Maestro não era democrático na escolha do repertório cantado nas aulas e nas apresentações dos conjuntos de canto coletivo do instituto. Carolina Miguez Macedo, ao relatar suas experiências no instituto, destacou: "o maestro era genial! Suas escolhas para as apresentações eram magníficas! Tudo sempre com muita energia. Também, com um 
temperamento daqueles que nos amedrontava. [...] não podíamos errar e nem resmungar das músicas que ele escolhia. Ele tinha um ouvido" (MACEDO, 2011).

Para o signatário do Manifesto dos Pioneiros da Educação Nova, o trabalho do Maestro era diferenciado, pois "por circunstâncias explicáveis na vida de nossos artistas, Villa-Lobos andou a trabalhar no estrangeiro, em toda mocidade e só agora, quando o seu poder de criação se acha em plena maturidade, é que veio dedicar ao Brasil na extraordinária atividade de que é capaz" (ANÍSIO TEIXEIRA apud VILLA-LOBOS, 1937, p.34).

Ainda nessa perspectiva de viagens de formação, Anísio, além de ressaltar as experiências de Villa-Lobos no exterior, também apoiava as estadas do Maestro em outros países. Nas suas correspondências como diretor geral do Departamento de Educação há registros das mediações que fazia com o prefeito do Distrito Federal, solicitando a liberação dos afazeres do músico no instituto; e também na liberação de recursos para as viagens que o diretor comissionava. Como consta no ofício assinado por Anísio em 3 de maio de 1935: "Comunico-vos, para os devidos fins, que o Exmo. Sr. Prefeito, em exercício, resolveu aprovar a proposta constante do oficio 392/DG, comissionando-vos para proceder, na República da Argentina, a estudos de vossa especialidade" (TEIXEIRA, 1935, p.1).

Percebe-se que o músico brasileiro esteve bastante vinculado a Anísio Teixeira, num trabalho de condução da sociedade brasileira às conquistas entendidas como modernas no período, patamares já alcançados por países desenvolvidos, a exemplo dos Estados Unidos da América, onde o signatário e apoiador do canto coletivo escolar estudou. Muitas das ideias do projeto orfeônico e projeção do grupo vocal e das aulas de Música e Canto Orfeônico do Instituto, possivelmente, só foram à frente pelo apoio dele, por sua liderança na diretoria da Instrução Pública do Distrito Federal.

\section{AFRÂNIO PEIXOTO: MÚSICA COMO GINÁSTICA PARA OS PULMÕES}

As relações do Maestro com outros gestores do Instituto de Educação do Rio de Janeiro, na Era Vargas, também foram importantes. O que pudemos verificar nas comunicações de Villa-Lobos com Afrânio Peixoto, professor de História da Educação do Instituto, Reitor da instituição no período em que fez parte da Universidade do Distrito Federal. Por meio dessas correspondências, constatamos os registros de admiração e o compartilhar de ideias do médico com o Maestro. Como explica Mignot (2005), esse tipo 
de diálogo era uma estratégia de comunicação no contexto das redes de sociabilidade de muitos intelectuais e educadores na Era Vargas, que, com muitos afazeres, ficavam com os contatos pessoais limitados e tinham nas mensagens por escrito uma alternativa.

Dentre as cartas trocadas entre Afrânio Peixoto e o Maestro, merece destaque o valor que o professor da Universidade do Distrito Federal deu à obra pedagógica villalobiana, cantada pelos Orfeões do Instituto e nas aulas de Música e Canto orfeônico. Os registros indicam que as peças folclóricas, com uma transposição didática, sensibilizavam o médico professor de História da Educação. O signatário do Manifesto da Educação Nova sinalizou que a obra nacionalista é admirável, e que ao analisar o livro, ele pôde recordar-se de muitos momentos de sua infância, pois as músicas compiladas no cancioneiro pelo Maestro eram um fomento à memória dos brasileiros das diferentes regiões do país.

Meu Caro Maestro e Amigo:

Percorri o livro, comovi-me à recordação de tantas coisas da infância.

Esta obra nacionalista é admirável. Reaver o disperso, salvar o esquecido e esquecível; estilizar o agreste e o popular é dar aos nossos jovens e às nossas crianças, da capital e depois de todo Brasil, um banquete de saúde e cantigas de todos nós, de ontem e de hoje. Uma alma melódica comum é o que fez. Muito e muito obrigado!

Você que faz genialmente, Villa-Lobos, faz igualmente assim a obra de "Maestro Povo". Obrigado por este cancioneiro, de minha devoção, como o outro.

Seu admirador e amigo,

Afrânio Peixoto. (PEIXOTO, sem data(a), p.1) ${ }^{1}$

Como destaca Vieira (2010), a exaltação estratégica de certas obras pode ser entendida como ferramenta para ressaltar a enunciação de uma ideologia e convênio entre os intelectuais. Assim, a carta de Afrânio Peixoto parece tratar de uma aliança do higienista, professor e reitor com o educador musical. Em outras palavras, o crédito e o prestígio que o maestro conquistou do médico e professor de História da Educação podem ser entendidos como uma voz autorizativa. Entende-se a correspondência como uma espécie de chancela, um reconhecimento da obra pedagógica de Villa-Lobos e, por consequência, de seu projeto musical-pedagógico.

\footnotetext{
${ }^{1}$ Tivemos acesso às cópias das cartas trocadas entre o Maestro e Afrânio Peixoto no Museu Villa-Lobos, porém os originais estão na Academia Brasileira de Letras. (Fonte: Academia Brasileira de Letras - 10. ABL.03).
} 
$\mathrm{Na}$ carta de Afrânio não há evidências sobre a qual cancioneiro ele estava se referindo; também não está datada. Assim, há certa dificuldade de identificação da obra villalobiana a que se refere. Percebe-se que é um dos hinários orfeônicos, porque o autor indica no texto os jovens e as crianças como o público-alvo da obra. E, escrevendo "como o outro", é possível que ele esteja se referindo ao Canto Orfeônico Volume II, ou, então, ao Volume II da coleção Solfejos, pois as coleções foram constituídas por dois volumes.

Há, nas palavras do médico, destaque para o caráter nacionalista da obra. Esse aspecto era um elemento de imbricamento do projeto musical com os signatários do Manifesto, pois havia entre esses educadores alguns aspectos semelhantes ao que formula Libânia Xavier: "a preocupação com a organização do Estado e a construção da nacionalidade ocupava o centro da vida cultural, nas artes, na literatura e em outros setores da atividade intelectual" (XAVIER, 2003, p.10). Nessa perspectiva, a identidade nacionalista era construída pela música escolar orfeônica que buscava, com o auxílio dos elementos do folclore, a projeção de uma expressão estética para a promoção da identidade cultural brasileira legítima.

A proposta escolanovista de Afrânio Peixoto vinculava-se, dentre outros aspectos, com a perspectiva higienista que transitava entre os educadores e médicos, desde a Corte Imperial. Os esforços na busca de uma nação saudável ligavam-se aos investimentos do governo de Getúlio Vargas para que o Brasil caminhasse rumo ao progresso econômico. Havia como parâmetro e modelo os países da Europa, onde Afrânio foi buscar novos conhecimentos. Ideias que conquistaram mais espaço no Brasil com seus esforços (GONDRA, 2011).

O médico educador elaborou - juntamente com Graça Couto, na época diretor geral dos Serviços de Saúde Pública do Rio de Janeiro e diretor dos Serviços de Profilaxia e Desinfecção - um manual direcionado à Escola Normal, chamado Noções de Hygiene (1914). A publicação estava fundamentalmente embasada em um compêndio de higiene de Afrânio que, em 1913, havia sido editado como um dos principais tópicos do Tratado de Medicina Pública. Afrânio Peixoto, no prefácio da obra de 1914, afirmou que dedicar à escola de formação de professores o manual de higiene, com técnicas, e conhecimentos considerados modernos e úteis à proteção e ao bem da saúde, era uma expressão de amor à pátria (MAIO, 1994).

Segundo Oliveira (2004), no seu estudo sobre o canto como um instrumento de civilidade na escola, no século passado, o canto coletivo no Brasil, seguindo o modelo 
europeu e norte americano, estava articulado com a educação higienista na medida em que a prática vocal demanda um exercício respiratório que interfere nos pulmões, na circulação sanguínea e na oxigenação fundamental para o bom funcionamento da mente. Nessa direção, afirma que:

No contexto de uma educação estética voltada para a assimilação dos novos padrões de civilidade, cuja prescrição às crianças se tornava cada vez mais constante, a educação musical, mais especificamente o canto escolar, foi se constituindo em uma estratégia capaz de atingir esse fim. Por meio do canto, educar-se-iam não somente o sentido da audição, mas também o ritmo corporal, a respiração, a voz, além do gosto e dos sentimentos cívico e moral. Logo, grande parte do poder educativo da música vocal estava no fato de que entoar canções poderia proporcionar uma sintonia com os ritmos naturais do corpo, notadamente no que dizia respeito à frequência dos batimentos cardíacos ou dos movimentos de inspiração e expiração. Tal sintonia, além de regular os movimentos do corpo, prepararia o cantor, ou mesmo o ouvinte, para uma assimilação quase orgânica da mensagem textual das canções (OLIVEIRA, 2004, p. 83-84).

No que se referem ao moderno, percebo nas trilhas percorridas pelos educadores no instituto, dentre eles Afrânio Peixoto e Villa-Lobos, que eles estavam bastante harmonizados por entenderem o canto como uma ginástica respiratória. O Maestro sinalizou nos objetivos e finalidades do Canto Orfeônico que os exercícios respiratórios devem ser disciplinarmente realizados (VILLA-LOBOS, 1940), mais um aspecto que pode ter sido utilizado para a legitimação da música na instituição. Uma vez que se procurava a utilização de métodos sofisticados de ensino para o aproveitamento eficaz dos discentes, considerando o corpo e a mente, também respeitando as limitações vocais dos alunos. Como também, segundo Josefina Figueiredo Antunes - aluna do Instituto no período -, poupando os pais que temiam as escolas especializadas de música do Rio de Janeiro, que pretendiam tornar "as crianças ainda pequenas em cantores, em vozes prodígio com idade precoce, que passavam exercícios de canto para adultos" (ANTUNES, 2012), atividades que podem lesar o aparelho fonador ainda não totalmente desenvolvido.

Nesse diálogo da música com a saúde, as aulas de Canto Orfeônico, os Orfeões Artístico e Geral do Instituto eram articuladas aos objetivos higienistas pela capacidade de contrabalançar o fazer mental por meio lúdico. O canto coletivo para os higienistas, dentre outros benefícios, era considerado um elemento capaz de proporcionar leveza num contexto de denso trabalho mental, envolvendo a formação docente e o trabalho com as 
crianças que demandavam muita energia. Nessa perspectiva, o canto coletivo era pensado na escola:

[...] como veículo de formação harmônica do corpo e do espírito, uma vez que contemplava os educandos, simultaneamente, com a cultura das 'faculdades físicas, intelectuais e morais', no sentido do melhoramento do indivíduo e da espécie. Essa visão de escola modeladora, que não só aperfeiçoava o espírito como também conformava o corpo, fazia ver como indispensável a presença de novos saberes a compor o universo da escola. Assim, a higiene era um exemplo nesta tarefa (MARQUES,1994, p. 101).

Isso posto, considero a relação da prática orfeônica ao "descanso", como um recurso profilático e como um elemento de desenvolvimento físico dos indivíduos no entender dos escolanovistas. As ideias musicais pedagógicas villalobianas parecem vir à baila nos parâmetros de qualidade higienistas que propagavam os médicos e os educadores. No período, o Maestro divulgava que "o canto coral fortalece o corpo e espírito. Amplia o fôlego dos fracos; disciplina suavemente os impacientes e os tardos" (VILLA-LOBOS, 2009, 7).

Além disso, na relação de Afrânio Peixoto e Villa-Lobos, havia outras afinidades e "orquestrações". As cartas revelam que o reitor apreciava e recomendava a utilização dos cancioneiros nos arraiais do instituto, mas também fazia uso dos créditos de sua boa relação com o Maestro. Como na carta que segue citada:

\section{Meu Caro Villa-Lobos,}

Terei crédito para tanto?

Quisera pedir-lhe, para filha de amigo meu, muito caro, um lugar de auxiliar contratado do Serviço de Música e Canto Orfeônico. Ela é diplomada pelo Conservatório de Música e sua admiradora, do artista e do mestre. Dê-me pelo menos uma esperança.

Seu amigo e admirador,

Afrânio Peixoto. (PEIXOTO, sem data (b), p.1)

As correspondências indicam que o reitor referendava o Canto Orfeônico e suas aproximações ideológicas como projeto musical-pedagógico, mas, ao mesmo tempo, a correspondência supracitada demonstra que o Maestro abria espaço para o seu remetente. Pois, há na carta uma sinalização na marginália que indica que o pedido foi atendido, em 10 de março de 1936, acompanhado de uma rubrica que não foi possível identificar. Esse documento reafirma a constatação de Mignot (2005) ao analisar as cartas de Anísio

\footnotetext{
${ }^{2}$ Fonte: Academia Brasileira de Letras - 10.ABL.01.
} 
Teixeira, que também faziam parte dessa rede de sociabilidade, indicando que amigos escreviam cartas em prol de seus interesses particulares; entretanto, em parte significativa das vezes, fizeram os textos para pedir por outros postulantes.

$\mathrm{Na}$ correspondência, ao invocar "a amizade que os unia [faziam] solicitações de emprego para os cargos" (MIGNOT, 2005, p.61). Por um lado, constatamos que Afrânio Peixoto e Villa-Lobos eram homens públicos que, além de se relacionarem em prol da Arte e da Educação Higienista no Instituto, também intercediam pelos amigos. Por outro lado, há no documento o registro de um acordo entre dois intelectuais que ocupavam cargos de gestão no governo de Getúlio Vargas. Assim, neste estudo relativo a uma prática musical numa instituição pública, verificamos a mediação que, segundo Faria, "enfraquece os critérios universalistas, públicos e democráticos em detrimento de uma ordem particularista" (FARIA, 2011, p.63).

Pelo que percebemos, as ideias de Afrânio Peixoto e do músico nacionalista, nesse contexto da década de 1930, estavam associadas aos ideais higienistas, como uma prática saudável para cuidar do espírito, suavizando a elaboração intelectual, as jornadas de trabalho e o longo tempo de estudos que as disciplinas demandavam, como um exercício respiratório para revigorar o corpo. Nessa direção, parece que o Canto Orfeônico era compreendido como um elemento necessário para o equilíbrio na escola. Assim, o canto coletivo no Instituto de Educação perpassava por ambos interesses civilizatórios: o cuidado com a saúde e a educação cívica.

\section{FERNANDO DE AZEVEDO: APROXIMAÇÕES EM MEIO AOS DESENCONTROS}

Além de primeiro signatário, Fernando de Azevedo foi o redator do Manifesto da Educação dos Pioneiros da Educação Nova, documento escrito em resposta ao presidente Getúlio Vargas, que solicitou aos educadores presentes na $4^{a}$ Conferência Nacional de Educação as bases para uma política da Revolução de 1930. Em outras palavras, o sociólogo respondeu a Vargas, que fomentou a produção coletiva dos fundamentos políticos e pedagógicos para aquele período histórico no qual o Canto Orfeônico foi consolidado no Brasil e o Orfeão Artístico do instituto implantado.

Neste estudo, que envolve o Instituto de Educação e o Canto Orfeônico, entendemos ser relevante abordar as aproximações e distanciamentos do redator do Manifesto com o projeto orfeônico, principalmente por acontecer na disciplina Música e 
Canto Orfeônico práticas pedagógicas bastante vinculadas aos ideais de Azevedo. Também é sabido que o intelectual planejou e executou um amplo movimento de construções de edifícios escolares, entre os quais o complexo da rua Mariz e Barros é o mais imponente, destinado inicialmente à antiga Escola Normal. Outra justificativa que merece ser destacada, para um contraponto com as ideias de Fernando de Azevedo no presente estudo, é a atenção direcionada pelo educador ao ensino da música nas suas produções intelectuais.

Segundo Jannibelli, no seu estudo sobre a história da educação musical, Anísio Teixeira deu continuidade, em 1932, ao que já estava estruturado por Fernando de Azevedo para consolidação de políticas educacionais democráticas e a gestão orgânica da instrução pública, incluindo o Canto Orfeônico no Instituto de Educação do Rio de Janeiro. Nas palavras de Emilia Danniballe Jannibelli:

[...] na então Capital do país, a Reforma de Anísio Teixeira, em 1932, que já encontrou estruturada a de seu antecessor, Fernando de Azevedo, a qual, em virtude da Revolução de 1930, não pôde ter o desenvolvimento almejado. Na Reforma de 1932, a Música e as demais Artes têm um lugar proeminente nas instituições de ensino, como um dos mais preciosos alicerces da Escola Nova. Além da programação para Escolas Elementares, Jardins de Infância e Ginásios, é criada a Cadeira de Música e Canto Orfeônico no Instituto de Educação (JANNIBELLI, 1971, p.42).

Assim, a partir da constatação de Jannibelli, fazemos nesta investigação, no que se refere a Fernando de Azevedo, um esforço para o aprofundamento e avanço do que já foi produzido por Lemos Junior (2005) e Lisboa (2005), por meio de uma articulação com os documentos e com relatos sobre o Canto Orfeônico no Instituto de Educação do Rio de Janeiro, iluminando especificidades que podem trazer à baila novas descobertas que reafirmam ou descaracterizam algumas ideias entendidas como consonantes entre ambos, Fernando de Azevedo e Villa-Lobos. Em outras palavras, buscamos contribuir, apontando os contrastes do escrito por Lemos Junior (2005, 2010) e Alessandra Lisboa (2005) com o objeto aqui investigado.

Para Fernando de Azevedo, a Arte era importante na formação dos professores. O programa de formação docente deveria, de maneira articulada, combinar a cultura utilitária e os estudos desinteressados, o espírito científico e o espírito artístico, as necessidades de cultura e do preparo especializado. Nessa direção, Lemos Junior (2005) - no seu estudo sobre o ensino da música, na modalidade orfeônica nas escolas secundárias públicas de Curitiba de 1931 a 1956 - destaca que Fernando de Azevedo entendia a relevância da arte no contexto da Educação Nova, abarcando as diferentes linguagens artísticas; porém, 
segundo as análises do pesquisador, a concepção de Azevedo sobre a arte na escola era utilitarista. E, nesse sentido, a música não assumia um papel essencial na perspectiva técnica e teórica; o foco era o potencial recreativo da música.

A percepção de Lemos Junior é pertinente na medida em que se constata que nas escolas de uma maneira geral não houve foco na formação musical profissional. Entretanto, no contexto do Instituto de Educação do Rio de Janeiro, essa questão pode ser aperfeiçoada, pois ali, com apoio de Anísio Teixeira, quando vinculada à Universidade do Distrito Federal, havia a possibilidade das professorandas se especializarem em música com uma abordagem técnica e teórica. O depoimento do musicólogo Eurico Nogueira França $^{3}$ evidencia o contraste ao relatar:

Eu fui aluno de Villa-Lobos na Universidade do Distrito Federal, que se fundou no Rio, em 1936, por aí. Entrei em 1937 como aluno da U.D.F., cuja principal figura era o Anísio Teixeira. A U.D.F. Ali houve uma experiência universitária do mais alto nível que foi a do Anísio Teixeira, em que havia um curso de música entre outras coisas. Este curso de música era dirigido por Villa-Lobos [...]. Quando eu entrei, já existia a universidade e o curso de música foi [...] no Instituto de Educação na rua Mariz e Barros. (FRANÇA apud PAZ, 1989, p.75).

Ou seja, o Instituto de Educação do Rio de Janeiro estava no caminho do "sonho de Anísio de institucionalizar o estudo científico da educação, o que permitiria superar o tratamento meramente empiricista que até então se dispensava no país aos problemas educacionais" (MENDONÇA, 2002, p.41). Pelo que parece no relato, a realidade do instituto com a presença de Villa-Lobos e a qualidade da performance e técnica, estavam mais próximas das ideias de Anísio e além das expectativas pedagógicas musicais de Fernando de Azevedo, pois havia uma abordagem da música como expressão artística específica, com leitura e escrita própria, diferente do contexto analisado por Lemos Junior (2005, 2010).

\footnotetext{
${ }^{3}$ Eurico Nazaré Nogueira França, crítico e musicólogo carioca, nasceu em 28 de maio de 1913. Formou-se em medicina pela Faculdade Nacional de Medicina em 1934, e em piano, no ano seguinte, pela Escola Nacional de Música da antiga Universidade do Brasil. Nessa instituição, ganhou a medalha de ouro de piano, em 1937. Deu continuidade a seus estudos de piano com Tomás Terán e ingressou no curso de formação de professores de canto orfeônico da Universidade do Distrito Federal, formando-se em 1940. Nesse período já colaborava na "Revista Brasileira de Música", da qual chegou a ser redator-responsável. Foi redator da rádio MEC e, de 1944 a 1974, redator e crítico de música dos jornais "Correio da Manhã" e "Última Hora" e da revista "Manchete". Foi membro da comissão artística e cultural do Teatro Municipal, e fundador e presidente da Sociedade Brasileira de Teatro e Música. É fundador da cadeira $\mathrm{n}^{\circ} 35$ da Academia Brasileira de Música. Disponível em: <http://www.abmusica.org.br/html/fundador/fundador35.html >. Acessado em: 5 de março de 2013.
} 
Azevedo, no livro Novos Caminhos e Novos Fins: A nova política da educação no Brasil. Subsídios para uma história de quatro anos, publicado em 1937, - ao analisar sua reforma educacional idealizada e o que foi possível executar no Distrito Federal de 1927 até 1930 - não menciona o estudo técnico e teórico da música. Entretanto, no texto, o educador não aborda a música só como divertimento, entretenimento e recreação; ele escreveu que o Canto Orfeônico pode contribuir para aprofundar e consolidar as bases espirituais da formação, abrindo a sensibilidade da criança às atividades ideais, capazes de despertá-la e desenvolvê-la, sem prejuízo, antes como proveito das práticas cotidianas (AZAVEDO, 1958, p. 128-129). Como um dos pensadores da Escola Nova, Azevedo destaca a função socializadora da música, que fomentava no indivíduo o espírito de coletividade. As análises do educador sinalizam que a expectativa do novo estava no abandonar as práticas de educação musical, que focalizavam aspectos propedêuticos de instrução ou da utilização da música como um entretenimento, sem perpassar pela questão dos valores nacionalistas.

Nesse sentido, Lemos Junior (2010) destaca que Fernando de Azevedo criticava a música como algo sem fins pedagógicos. Aqui, acrescento ser possível entender que o educador sociólogo percebia, no contexto do Distrito Federal, a "arte, que até então se hospedava retraída, nos programas artísticos de festas escolares, para deleite dos pais, no seu encantamento pelos filhos, incorporou-se ao sistema de educação popular, como um dos principais fatores educativos e uma das mais poderosas forças de ação, equilíbrio e de renovação da coletividade" (AZAVEDO, 1958, p. 118). No aspecto rítmico, a música pulsava conforme "a solidariedade rítmica dos bailados e cantos corais, como, em geral, de todos os exercícios de conjunto" (AZAVEDO, 1958, p. 129).

Entendemos que é preciso considerar que a obra de Fernando de Azevedo, na qual constam essas afirmações, foi escrita em 1958, décadas depois da sua gestão como diretor geral da instrução pública do Distrito Federal. Ou seja, num período em que o Canto Orfeônico já estava bem estruturado no Instituto de Educação e no Rio de Janeiro. Portanto, existe a possibilidade de o educador ter articulado tais afirmações para juntar-se ao movimento pedagógico-musical, para ser considerado um dos incentivadores do projeto artístico que foi apoiado por Júlio Afrânio Peixoto e, principalmente, por Anísio Teixeira.

Alessandra Coutinho Lisboa (2005) também ressalta que para Azevedo o Canto Orfeônico atendia ao objetivo de propiciar ao cidadão o acesso ao ensino, e não apenas direcionava o ensino da música às minorias com melhores condições financeiras. Nessa 
perspectiva, o projeto villalobiano permitia oportunidades iguais de desenvolvimento musical, não influenciado por conveniências de classes e grupos específicos. O que não corresponde à realidade aqui em questão. Inicialmente, interrogamos: que cidadão é esse que o Canto Orfeônico se propunha a atender? Por exemplo, é muito provável que os índios, os trabalhadores do campo na Era Vargas não tivessem sido considerados no planejamento das aulas dessa disciplina. Menos provável ainda que esses cidadãos fossem cantores num Orfeão Artístico. Dessa forma, entendemos que Fernando de Azevedo não considerou a realidade que o Brasil vivenciava no período.

Assim como o acesso ao Instituto de Educação do Rio de Janeiro não era para todos que desejavam, o Canto Orfeônico praticado na escola sediada no prédio da rua Mariz e Barros também não. A instituição destinava-se aos poucos que conseguiam ser aprovados nos complexos e difíceis processos seletivos. Segundo Vidal, só uma "seleta parcela da classe média carioca que teve a oportunidade de estudar no monumental prédio" (VIDAL, 2005, p.15), localizado nas proximidades da Tijuca, ainda na década de 30 um bairro reconhecido pelo número de colégios de boa qualidade para a elite, tradição que teve início na penúltima década do século XIX. O instituto ficava perto do Colégio Militar, instalado desde 1889 no palacete do Conde de Bonfim e da Chácara do Barão de Itacuruçá, onde estava a imponente sede do Colégio Batista Shepard, construída em 1911.

Nesse contraponto, entre as ideias de Villa-Lobos e Fernando de Azevedo, percebemos as proximidades das ideias; mas ao tratar do Instituto de Educação do Rio de Janeiro constatamos que a realidade da instituição mostrava-se diferente na medida em que era um "exemplo prático de observância do modelo ideal" (VIDAL, 2005, p.15), de escola, distinta da realidade das classes populares. Entretanto, de um modo geral, mesmo com algumas particularidades do Instituto de Educação do Rio de Janeiro, entendemos que os intelectuais envolvidos no Manifesto estavam envolvidos diretamente com o Canto Orfeônico na instituição, como no caso de Anísio Teixeira e Afrânio Peixoto; ou indiretamente ligados por meio dos ideais nacionalistas, como Fernando de Azevedo.

\section{CONSIDERAÇÕES FINAIS}

Os signatários do Manifesto dos Pioneiros da Educação Nova, dentro do contexto do projeto villalobiano, podem ser entendidos como intelectuais progressistas que apoiaram um momento significativo da História da Educação Musical no Brasil, ao referendarem a música escolar - mais especificamente na modalidade canto coletivo - 
como um instrumento no processo longo de democratização da sociedade brasileira. A dinâmica desses pensadores ficou de alguma maneira conectada aos investimentos dos educadores musicais que lutavam em prol da garantia do ensino dessa arte no currículo; movimento que se configura até hoje como questão central para os pensadores da educação musical no Brasil. Enfim, juntamente com Xavier (2003), pensamos que o Manifesto, da mesma forma que as cartas de intenções referidas a questões educacionais - que muitas vezes precederam a promulgações de leis, medidas e ações - tornou-se relevante na compreensão de particularidades dos processos históricos e de organização dos acontecimentos no sistema público de ensino do Brasil.

Como resultado dos contrapontos entre as propostas de Villa-Lobos e as dos signatários, entendem-se proximidades dos ideais; porém, ao se tratar do Instituto de Educação do Rio de Janeiro, percebe-se que a conjuntura da instituição difere, na medida em que era um exemplo prático de observância do modelo ideal de escola, uma realidade distinta das comunidades educativas das classes populares.

Entretanto, de modo geral, mesmo considerando particularidades do Instituto de Educação do Rio de Janeiro, é possível compreender que os intelectuais envolvidos no Manifesto estavam diretamente ligados ao canto orfeônico na instituição - caso de Anísio Teixeira e Afrânio Peixoto -, ou indiretamente por meio dos ideais nacionalistas, a exemplo do educador Fernando de Azevedo.

\section{REFERÊNCIAS}

ANTUNES, Josefina Figueiredo. [18 de setembro de 2012]. Rio de Janeiro, RJ. Entrevista concedida ao autor.

AZEVEDO, Fernando. A formação do professor e a reforma. Boletim de Educação Pública. Distrito Federal I, (4): 848, out/dez. 1930.

AZEVEDO, Fernando. et al. Manifesto dos Pioneiros da Educação Nova. In: Revista Brasileira de Estudos Pedagógicos, $\mathrm{n}^{\circ}$ 70, 1960, parágrafo 10.

AZEVEDO, Fernando. Novos caminhos e novos fins: a nova política da educação no Brasil. Subsídios para uma história de quatro anos. 3. ed. São Paulo: Melhoramentos, 1958, p. 128-129.

BRASIL. LEI No 11.769, DE 18 DE AGOSTO DE 2008. Altera a Lei no 9.394, de 20 de dezembro de 1996, Lei de Diretrizes e Bases da Educação, para dispor sobre a obrigatoriedade do ensino da música na educação básica. Presidência da República: Casa Civil; Subchefia para Assuntos Jurídicos. Disponível em: 
$<$ http://www.planalto.gov.br/ccivil 03/ Ato2007-2010/2008/Lei/L11769.htm>, Acesso: 14 fev. 2019.

CHERNAVSKY, Anália. Um Maestro no Gabinete: música e política no tempo de VillaLobos. Dissertação (Mestrado em História). Instituto de Filosofia e Ciências Humanas, Universidade Estadual de Campinas, Campinas. 2003.

CÍVICA, Festa. O Globo. Rio de Janeiro, 27 de novembro de 1933, p. 3 (edição da manhã). Acervo do Museu Villa-Lobos

CONTIER, Arnaldo D. Passarinhada do Brasil: canto orfeônico, educação e getulismo. São Paulo: Edusc, 1998.

FARIA, Lia. Ciomar. Macedo. Chaguismo e Brizolismo: territorialidades políticas da escola fluminense. 01. ed. Rio de Janeiro: Quartet, 2011.

FAVERO, Maria de Lourdes de Albuquerque. O autoritarismo institucional e a extinção do IESAE. Educação e Sociedade. Campinas , v. 24, n. 85, p. 1257-1275, 2003.

GONDRA, José. Gondra. Artes de civilizar: medicina, higiene e educação escolar na Corte Imperial. 1. ed. Rio de Janeiro: EDUERJ, 2004.

GONDRA, José. Gondra Temperar a alma, retemperar os músculos: Corpo e História da Educação em Afranio Peixoto. Pro-Posições (UNICAMP. Impresso), v. 22, p. 19-34, 2011.

JANNIBELLI, Emilia. Danniballe. A Musicalização na escola. 1. ed., Estado da Guanabara, abr. 1971.

LE GOFF, Jacques. História e Memória. Tradução Bernardo Leitão, et all. $4^{\mathrm{a}}$ Ed. Campinas: UNICAMP, 2010.

LEMOS JÚNIOR, Wilson. Os defensores do ensino de música na escola brasileira durante a primeira metade do século XX. Revista Eletrônica de Musicologia (Ed. Portuguesa), v. XIV, p. 1, 2010.

LISBOA, Alessandra Coutinho. Villa-Lobos e o canto orfeônico: música, nacionalismo e ideal civilizador. Dissertação (Mestrado em Música). São Paulo: Instituto de Artes da Universidade Estadual Paulista (IA-Unesp), 2005.

LÜDKE, Menga e ANDRÉ, Marli. Pesquisa em educação: abordagens qualitativas. São Paulo: EPU, 1986.

MACEDO, Carolina Miguez. [10 de maio de 2011], Petrópolis, RJ. Entrevista concedida ao autor.

MAIO, Marcos. Chor. Afrânio Peixoto: Estratégias e Desventuras de um Intelectual na Vida Pública. Revista Ágora. Rio de Janeiro, Dept. História/UFF, v. 1, n. 2, p. 26-38, 1994. 
MAIO, Marcos. Chor. Afrânio Peixoto: Uma Trajetória Médica. Revista da Sociedade Brasileira de História da Ciência Revista Brasileira de História da Ciência, Rio de Janeiro, v. 1, n. 11, p. 75-81, 1994.

MARQUES, Vera. Regina. Beltrão. A Medicalização da Raça: Médicos, Educadores e Discurso Eugênico. 1a ${ }^{\text {a }}$ ed. Campinas: Editora da UNICAMP, 1994.

MENDONÇA, Ana Waleska. Anísio Teixeira e a Universidade de Educação. 1 ${ }^{\mathrm{a}}$. ed. Rio de Janeiro: EDUERJ, 2002.

MIGNOT, Ana. Chrystina Venancio. . O carteiro e o educador: práticas políticas na escrita epistolar. Revista Brasileira de História da Educação, São Paulo, v. 10, p. 45-69, 2005.

MINISTÉRIO DA EDUCAÇÃO. Presença de Villa-Lobos, Rio de Janeiro, MEC/DAC, MVL, 1970. V.5.

MOREIRA, H. e CALEFFE, L. G. Metodologia da Pesquisa para o Professor Pesquisador. Rio de Janeiro: DP\&A, p.174, 2006.

NÓVOA, António. Por que a História da Educação? In: STEPHANOU, Maria e BASTOS, Maria Helena. (Orgs.) Histórias e memórias da educação no Brasil, vol. I: séculos XVIXVIII. Petrópolis, RJ: Vozes, 2004.

OLIVEIRA, Flavio Couto e Silva de. O canto civilizador: música como disciplina escolar nos ensinos primário e normal de Minas Gerais, durante as primeiras décadas do século XX. Tese (Doutorado em Educação) - Faculdade de Educação, UFMG. 2004.

PAZ, Ermelinda Azevedo. Villa-Lobos o Educador. Prêmio Grandes Educadores Brasileiros 1988. Brasília, DF: INEP / MEC, 1989.

PEIXOTO, Júlio Afrânio [Carta] sem data (a), Rio de Janeiro [para] VILLA-LOBOS, Heitor. Rio de Janeiro. 1f. Apreciação de cancioneiro orfeônico. (Fonte: Academia Brasileira de Letras - 10.ABL.03)

PEIXOTO, Júlio Afrânio [Carta] sem data (b), Rio de Janeiro [para] VILLA-LOBOS, Heitor. Rio de Janeiro. 1f. Solicita contrato de professora de Música e Canto Orfeônico. (Fonte: Academia Brasileira de Letras - 10.ABL.01)

TEIXEIRA, Anísio. Educação Pública: administração e desenvolvimento. Relatório do diretor geral do departamento de Educação do Distrito federal: Anísio S. Teixeira, dez. 1934. Rio de Janeiro: oficina Gráfica do Departamento de Educação, 1935.

TEIXEIRA, Anísio Spinola. Ofício 421 do Gabinete do Diretor do Departamento de Educação. Assinado por Anísio Spinola Teixeira, endereçado a Heitor Villa-Lobos. Distrito Federal, em 3 de maio de 1935. Arquivo do Museu Villa-Lobos, Sessão Correspondências.

VIEIRA, Carlos Eduardo. A escrita da História da Educação no Brasil: formando professores através de noções de história". Anais do VIII Congresso Luso-Brasileiro de História da Educação, 2010, São Luís :EDUFMA, 2010. v. 1. 
VIDAL, Diana Gonçalves. O exercício disciplinado do olhar: livros, leituras e práticas de formação docente no Instituto de Educação do Distrito Federal (1932-1937). 1a. ed. Bragança Paulista: EDUSF, 2001.

VILLA-LOBOS, Heitor. Canto Orfeônico. $1^{\circ}$ volume. Rio de Janeiro: Irmãos Vitale Editora, 1940.

VILLA-LOBOS, Heitor. Educação Musical. Boletim Latino Americano de Música VI/6 abril de 1946.

VILLA-LOBOS, Heitor. Guia Prático para a educação artística e musical. 3 Caderno. Org. editorial: Valéria Peixoto; textos e pesquisa: Manoel Aranha Correa do Lago, Sérgio Barboza, Maria Clara Barbosa. Rio de Janeiro: ABM-FUNARTE, 2009.

VILLA-LOBOS, Heitor. O ensino popular da música no Brasil. Rio de Janeiro, Departamento de Educação do Distrito Federal, 1937.

VILLA-LOBOS, Heitor. SEMA: relatório geral dos serviços realizados de 1932 a 1936. Tomo III. Montevidéu, abril de 1937.

XAVIER, Libânia. Nacif. Manifestos, cartas, educação e democracia. In: Magaldi, Ana Maria; Gondra, José G. (Org.). A reorganização do campo educacional no Brasil: manifestações, manifestos e manifestantes. 1 ed. Rio de Janeiro: Sete Letras, 2003.

Recebido: 05/03/2019

Aceito: 30/03/2019 